\title{
Corticosteroids for the initial episode of steroid-sensitive nephrotic syndrome
}

\author{
Elisabeth M. Hodson ${ }^{1,2,3}$ • Deirdre Hahn ${ }^{2}$ • Jonathan C. Craig ${ }^{1,2,3}$
}

Received: 23 March 2015 /Revised: 24 March 2015 / Accepted: 24 March 2015 / Published online: 26 April 2015

(C) IPNA 2015

Keywords Nephrotic syndrome $\cdot$ Child $\cdot$ Corticosteroids

\section{Introduction}

The International Study of Kidney Disease in Children (ISKDC) arbitrarily determined a standard-dose prednisolone regimen for the first episode of nephrotic syndrome [1]. This comprised 4 weeks of daily prednisolone $\left(60 \mathrm{mg} / \mathrm{m}^{2} /\right.$ day; maximum dose $80 \mathrm{mg}$ ) followed by 4 weeks of prednisolone $\left(40 \mathrm{mg} / \mathrm{m}^{2} /\right.$ day; maximum dose $60 \mathrm{mg}$ ) given on 3 consecutive days out of 7 . After the Arbeitsgemeinschaft für Pädiatrische Nephrologie demonstrated in a randomized controlled trial (RCT) that alternate-day prednisolone therapy was more effective than intermittent doses of prednisolone in maintaining remission [2], alternate-day prednisolone dosing became the standard regimen for the second month of therapy. However, because of the high relapse rate with 2 months of prednisolone therapy, RCTs have investigated the benefits and harms of longer courses of therapy compared with 2 or 3 months.

Elisabeth M. Hodson

elisabeth.hodson@health.nsw.gov.au

1 Centre for Kidney Research, The Children's Hospital at Westmead, Locked Bag 4001, Westmead, Sydney, NSW 2145, Australia

2 Department of Nephrology, The Children's Hospital at Westmead, Sydney, Australia

3 Sydney School of Public Health, University of Sydney, Sydney, Australia

\section{Combining the evidence from RCTs}

In 2000 we published a systematic review of RCTs which evaluated corticosteroid therapy in children with their first episode of steroid-sensitive nephrotic syndrome (SSNS) [3]. In a meta-analysis of five RCTs (334 children), prednisolone administered for 3-7 months compared with 2 months in the initial episode of SSNS significantly reduced the risk of relapse at $12-24$ months by $27 \%$ [relative risk (RR) 0.73 ; $95 \%$ confidence intervals (CI) $0.60-0.89$ ) and reduced the number of children with frequently-relapsing nephrotic syndrome (FRNS) by $33 \%$ (RR 0.67; $95 \%$ CI 0.48-0.93). A metaanalysis of four additional RCTs (382 children), included in updates of the review to 2007, found that 6 months of prednisolone therapy significantly reduced the risk of relapse (RR 0.57; $95 \%$ CI 0.45-0.71) and the risk of FRNS (RR 0.55; $95 \%$ CI 0.39-0.80), when compared with 3 months [4]. No significant increase in adverse effects was identified.

\section{5 update of the systematic review}

Three large well-designed RCTs were published in 20132015 [5-7] which evaluated different durations of prednisolone therapy in children with their first episode of SSNS. In their RCT, Teeninga and co-workers [5] randomized 150 children to 3 months of prednisolone therapy and 3 months of placebo, or to 6 months of prednisolone therapy, with both groups receiving approximately the same total dose of prednisolone. The cumulative incidences of children with FRNS did not differ between treatment groups for up to 5 years, suggesting that the apparent benefit of prolonged treatment of SSNS resulted from the increased total dose of prednisolone-and not the duration of the therapy. Two subsequent RCTs, which included 246 and 180 children, respectively, 


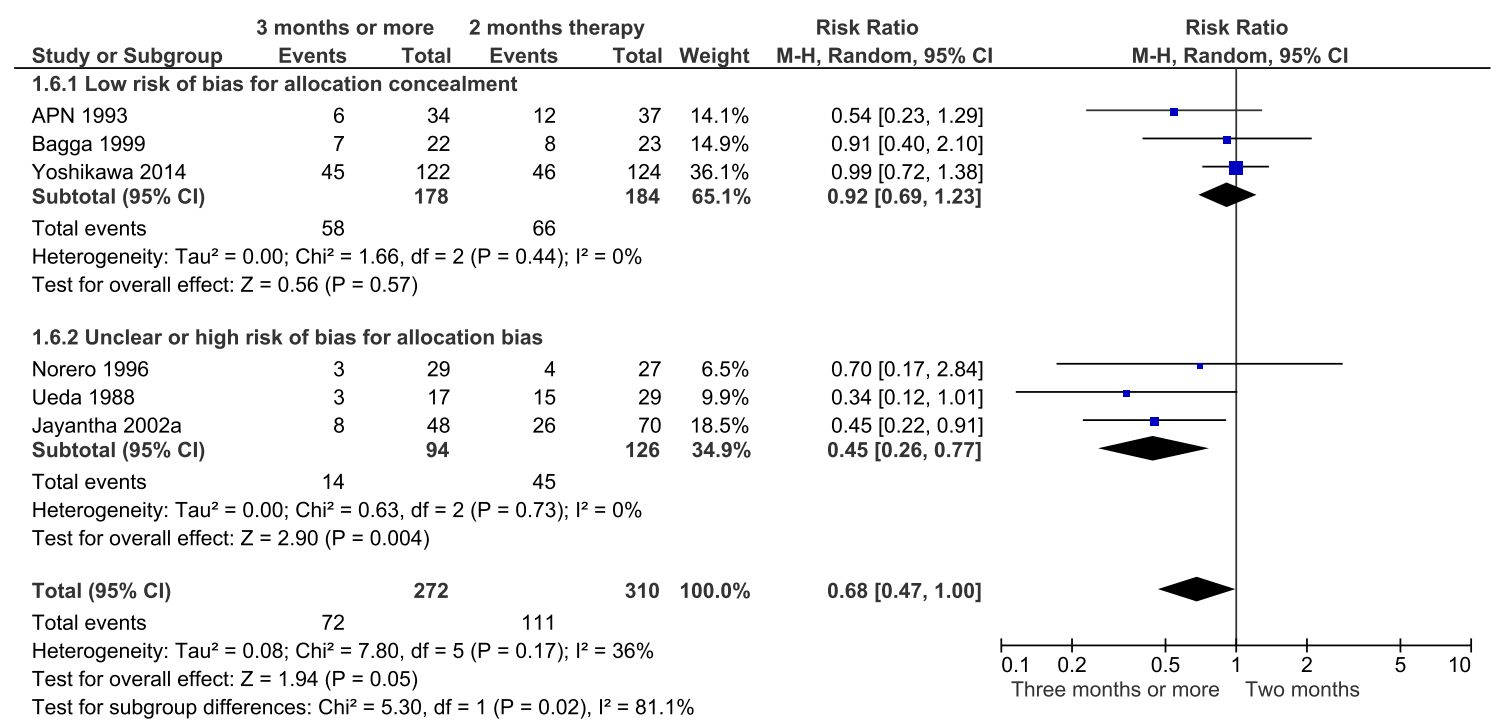

Fig. 1 Meta-analyses of the risk ratio [calculated using the MantelHaenszel $(M-H)$ random-effects method], with $95 \%$ confidence intervals $(C I)$, for developing frequently-relapsing nephrotic syndrome (FRNS) in six trials comparing $\geq 3$ months of prednisolone therapy with 2 months in the first episode of steroid-sensitive nephrotic syndrome (SSNS). Results

compared 2 [6] or 3 months [7] of prednisolone therapy with 6 months. Children treated for 6 months received higher cumulative doses of prednisolone than those treated for 2 or 3 months. The Indian study [7] was placebo controlled while the Japanese study [6] was open labelled. The numbers of children who suffered a relapse or developed FRNS at 12 months [7] or at 24 months [6] did not differ significantly between treatment groups. In the UK, recruitment has just been completed to a trial (PREDNOS) in which 2 months of prednisolone therapy is compared with 4 months, with the are divided into subgroups according to risk of bias for allocation concealment and are ordered by trial weights. $I^{2}$ Percentage of chi-squared statistic not explained by variation within studies, $d f$ degree of freedom. Reproduced with permission from Hahn et al. [9]

results expected in 2016-2017 after 24 months of follow-up [8].

We have updated the 2007 systematic review to include these three recently published trials and another small trial published in 2012 [9]. When all studies evaluating the duration of corticosteroid therapy in the first episode of SSNS were combined, the number of children relapsing by 12-24 months was significantly reduced in children treated for $\geq 3$ months compared with 2 months (8 studies, 741 children: RR 0.80; $95 \%$ CI 0.64-1.00) and in children treated for 5-6 months

\begin{tabular}{|c|c|c|c|c|c|}
\hline \multirow[b]{2}{*}{ Study or Subgroup } & \multicolumn{2}{|c|}{5 or 6 months } & \multicolumn{2}{|c|}{ Three months } & \multirow[b]{2}{*}{ Weight } \\
\hline & Events & Total & Events & Total & \\
\hline \multicolumn{6}{|c|}{ 2.6.1 Studies at low risk of bias for allocation concealment } \\
\hline Hiraoka 2003 & 10 & 36 & 15 & 34 & $20.4 \%$ \\
\hline Sinha 2014 & 36 & 92 & 35 & 89 & $28.8 \%$ \\
\hline $\begin{array}{l}\text { Teeninga } 2013 \\
\text { Subtotal }(95 \% \mathrm{Cl})\end{array}$ & 38 & $\begin{array}{r}64 \\
192\end{array}$ & 31 & $\begin{array}{r}62 \\
185\end{array}$ & $\begin{array}{l}30.0 \% \\
79.2 \%\end{array}$ \\
\hline Total events & 84 & & 81 & & \\
\hline \multicolumn{6}{|c|}{$\begin{array}{l}\text { Heterogeneity: } \mathrm{Tau}^{2}=0.02 ; \mathrm{Chi}^{2}=3.06, d f=2(P=0.22) ; \mathrm{I}^{2}=35 \% \\
\text { Test for overall effect: } Z=0.02(P=0.98)\end{array}$} \\
\hline \multicolumn{6}{|c|}{ 2.6.2 Studies at high or unclear risk of bias for allocation concealn } \\
\hline Mishra 2012 & 1 & 37 & 1 & 37 & $2.5 \%$ \\
\hline $\begin{array}{l}\text { Sharma } 2000 \\
\text { Subtotal }(95 \% \mathrm{Cl})\end{array}$ & 8 & $\begin{array}{r}70 \\
107\end{array}$ & 24 & $\begin{array}{r}70 \\
107\end{array}$ & $\begin{array}{l}18.3 \% \\
20.8 \%\end{array}$ \\
\hline Total events & 9 & & 25 & & \\
\hline \multicolumn{6}{|c|}{$\begin{array}{l}\text { Heterogeneity: } \text { Tau }^{2}=0.00 ; \mathrm{Chi}^{2}=0.58, \mathrm{df}=1(P=0.45) ; \mathrm{I}^{2}=0 \% \\
\text { Test for overall effect: } Z=2.86(P=0.004)\end{array}$} \\
\hline Total $(95 \% \mathrm{Cl})$ & & 299 & & 292 & $100.0 \%$ \\
\hline Total events & 93 & & 106 & & \\
\hline \multicolumn{6}{|c|}{$\begin{array}{l}\text { Heterogeneity: } \mathrm{Tau}^{2}=0.15 ; \mathrm{Chi}^{2}=12.05, \mathrm{df}=4(P=0.02) ; I^{2}=67 \% \\
\text { Test for overall effect: } Z=1.07(P=0.28)\end{array}$} \\
\hline
\end{tabular}

Fig. 2 Meta-analyses of the risk ratio (calculated using the $\mathrm{M}-\mathrm{H}$ random-effects method), with $95 \% \mathrm{CI}$, for developing FRNS in five trials comparing 5 or 6 months of prednisolone therapy with 3 months in the
Risk Ratio Risk Ratio

, Random, 95\% CI $0.63[0.33,1.20]$ $1.00[0.69,1.43]$ $1.19[0.86,1.64]$ $1.00[0.74,1.34]$

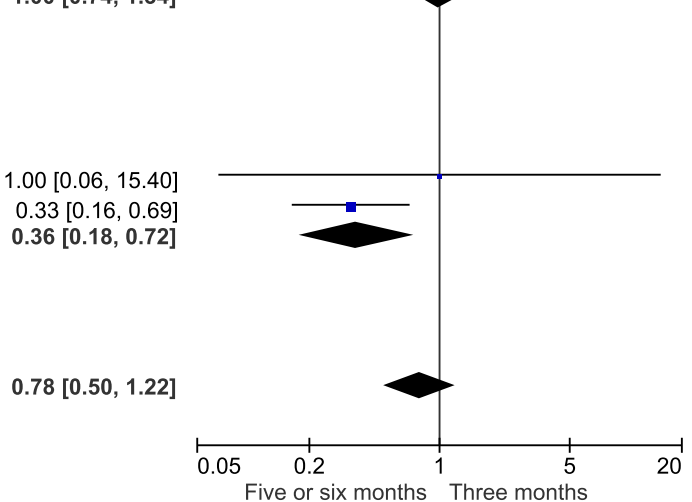

first episode of SSNS. Results are divided into subgroups according to risk of bias for allocation concealment and are ordered by trial weights. Reproduced with permission from Hahn et al. [9] 


\begin{tabular}{|c|c|c|c|c|c|}
\hline \multirow[b]{2}{*}{ Study or Subgroup } & \multicolumn{2}{|c|}{5 or 6 months } & \multicolumn{2}{|c|}{ Three months } & \multirow[b]{2}{*}{ Weight } \\
\hline & Events & Total & Events & Total & \\
\hline \multicolumn{6}{|c|}{ 2.7.1 Low risk of bias for blinding } \\
\hline Sinha 2014 & 36 & 92 & 35 & 89 & $28.2 \%$ \\
\hline $\begin{array}{l}\text { Teeninga } 2013 \\
\text { Subtotal }(95 \% \mathrm{Cl})\end{array}$ & 51 & $\begin{array}{r}64 \\
156\end{array}$ & 48 & $\begin{array}{r}62 \\
151\end{array}$ & $\begin{array}{l}33.8 \% \\
62.1 \%\end{array}$ \\
\hline Total events & 87 & & 83 & & \\
\hline \multicolumn{6}{|c|}{$\begin{array}{l}\text { Heterogeneity: } \mathrm{Tau}^{2}=0.00 ; \mathrm{Chi}^{2}=0.03, \mathrm{df}=1(\mathrm{P}=0.85) ; \mathrm{I}^{2}=0 \% \\
\text { Test for overall effect: } Z=0.26(P=0.79)\end{array}$} \\
\hline \multicolumn{6}{|c|}{ 2.7.2 High or unclear risk of bias for blinding } \\
\hline Mishra 2012 & 1 & 37 & 1 & 37 & $2.1 \%$ \\
\hline Sharma 2000 & 8 & 70 & 24 & 70 & $16.9 \%$ \\
\hline $\begin{array}{l}\text { Hiraoka } 2003 \\
\text { Subtotal }(95 \% \mathrm{Cl})\end{array}$ & 10 & $\begin{array}{r}36 \\
143\end{array}$ & 15 & $\begin{array}{r}34 \\
141\end{array}$ & $\begin{array}{l}19.0 \% \\
37.9 \%\end{array}$ \\
\hline Total events & 19 & & 40 & & \\
\hline \multicolumn{6}{|c|}{$\begin{array}{l}\text { Heterogeneity: } \mathrm{Tau}^{2}=0.00 ; \mathrm{Chi}^{2}=1.95, \mathrm{df}=2(\mathrm{P}=0.38) ; \mathrm{I}^{2}=0 \% \\
\text { Test for overall effect: } Z=2.96(P=0.003)\end{array}$} \\
\hline Total $(95 \% \mathrm{Cl})$ & & 299 & & 292 & $100.0 \%$ \\
\hline Total events & 106 & & 123 & & \\
\hline \multicolumn{6}{|c|}{$\begin{array}{l}\text { Heterogeneity: } \text { Tau }^{2}=0.12 ; \mathrm{Chi}^{2}=12.74, \mathrm{df}=4(\mathrm{P}=0.01) ; \mathrm{I}^{2}=69 \% \\
\text { Test for overall effect: } Z=1.27(\mathrm{P}=0.20)\end{array}$} \\
\hline
\end{tabular}

Risk Ratio

Risk Ratio

H, Random, 95\% Cl

M-H, Random, $95 \% \mathrm{Cl}$

$1.00[0.69,1.43]$

$1.03[0.86,1.24]$

$1.02[0.87,1.20]$

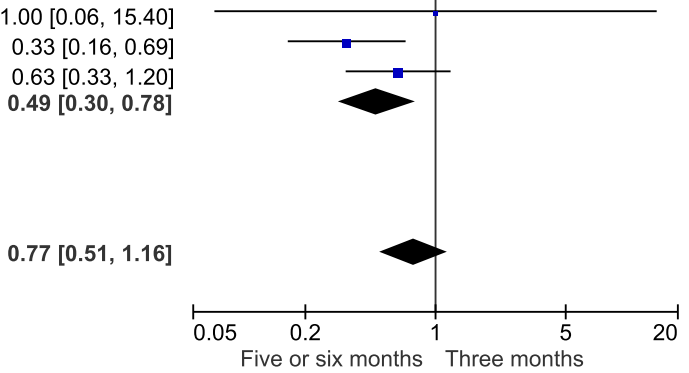

Fig. 3 Meta-analyses of the risk ratio (calculated using the $\mathrm{M}-\mathrm{H}$ random-effects method), with $95 \% \mathrm{CI}$, for developing FRNS in five trials comparing 5 or 6 months of prednisolone therapy with 3 months in the

first episode of SSNS. Results are divided into subgroups according to risk of bias for blinding (performance and detection bias) and are ordered by trial weights. Reproduced with permission from Hahn et al. [9]

compared with 3 months (7 studies, 763 children: RR 0.62; $95 \%$ CI $0.45-0.85$ ). The number of children developing FRNS was significantly reduced in children treated for $\geq 3$ months compared with 2 months ( 6 studies, 582 children: RR $0.68 ; 95 \%$ CI $0.47-1.00$ ), but there was no significant difference in the number of children developing FRNS between those treated for 5-6 months and and those treated for 3 months (5 studies, 591 children: RR 0.78; $95 \%$ CI $0.50-$ 1.22). However, the inclusion of these four trials led to a substantial heterogeneity among the studies ( $\left.I^{2} 36-83 \%\right)$ which could not be explained by chance alone. This heterogeneity (inconsistency or variability) in the results across studies had not been present in the earlier versions of the review.

\section{Investigation of heterogeneity in meta-analyses}

To investigate the differences between the results of metaanalyses in the previous versions of the systematic review and the 2015 update, we examined the risk of bias as a source of the heterogeneity. Other sources of heterogeneity (chance and clinical) were not realistic sources of bias, given the beyond-chance heterogeneity observed (very high $I^{2}$ values) and the observation that the two treatment arms were fairly consistent across the trials. It has been well established that studies with a high or unclear risk of bias for allocation concealment or blinding may exaggerate the efficacy of the experimental therapy by $30-40 \%[10,11]$ or by $17 \%$, respectively [10], compared with studies with a low risk of bias. These observations are explained by selection and performance/detection biases, respectively, whereby patients

may be allocated differently to experimental and control groups and managed differently within these groups so that any differences in results cannot be ascribed entirely to the intervention being investigated in the trial. For the outcome of FRNS, we carried out sub-group analyses to compare the results of studies at low risk of bias for allocation concealment (Figs. 1, 2) or blinding (Fig. 3) with those at high or unclear risk of bias. In studies at low risk of bias for allocation concealment or for performance and detection bias (blinding), there were no significant differences in the risk of FRNS between an extended duration of prednisolone therapy and treatment for 2 or 3 months. In contrast, in studies at high or unclear risk of bias for allocation concealment or blinding, an extended duration of prednisolone therapy significantly reduced the risk of FRNS compared with treatment for 2 or 3 months. Similar results were obtained for the outcome of first relapse by $12-24$ months. Thus, the heterogeneity among the studies can be explained by differences in methodological quality (risk of bias). The studies included in the systematic review published in 2000 [3] and in the updates to 2007 [4] were generally of high or unclear risk of bias. Only three studies showed adequate allocation concealment [12-14], and no studies were blinded. In contrast, three [5-7] of the four studies added to the 2015 update demonstrated adequate allocation concealment, and two studies were blinded [5, 7].

\section{Conclusions}

The addition of recently published, well-designed trials to the Cochrane systematic review examining the benefit of 
corticosteroids in the initial episode of SSNS has changed the conclusions of the review. Prolonging prednisolone therapy for 6 months does not reduce the risk for relapse compared with 2 or 3 months of therapy in children aged 1-17 years at presentation. Meanwhile, in response to these new data, guidelines should recommend treatment durations of 2 or 3 months for the management of the first episode of SSNS, rather than longer durations, as currently recommended in the Kidney Disease/Improving Global Outcomes (KDIGO) guidelines [15].

\section{References}

1. Abramowicz M, Barnett HL, Edelmann CM Jr, Greifer I, Kobayashi O, Arneil GC, Barron BA, Gordillo-P G, Hallman N, Tiddens HA (1970) Controlled trial of azathioprine in children with nephrotic syndrome. A report for the international study of kidney disease in children. Lancet 1:959-961

2. (1981) Alternate-day prednisone is more effective than intermittent prednisone in frequently relapsing nephrotic syndrome. A report of Arbeitsgemeinschaft für Pädiatrische Nephrologie. Eur J Pediatr 135:229-237

3. Hodson EM, Knight JF, Willis NS, Craig JC (2000) Corticosteroid therapy in nephrotic syndrome: a meta-analysis of randomised controlled trials. Arch Dis Child 83:45-51

4. Hodson EM, Willis NS, Craig JC (2007) Corticosteroid therapy for nephrotic syndrome in children. Cochrane Database Syst Rev 4: CD001533

5. Teeninga N, Kist-van Holthe J, van Rijskwijk N, de Mos N, Wetzels JF, Nauta J (2013) Extending prednisolone therapy does not reduce relapse in childhood nephrotic syndrome. J Am Soc Nephrol 24: 149-159

6. Yoshikawa N, Nakanishi K, Sako M, Oba MS, Mori R, Ota E, Ishikura K, Hataya H, Honda M, Ito S, Shima Y, Kaito H, Nozu K, Nakamura H, Igarashi T, Ohashi Y, Iijima K (2015) A multicenter randomized trial indicates initial prednisolone treatment for childhood nephrotic syndrome for two months is not inferior to six-month treatment. Kidney Int 87:225-232

7. Sinha A, Saha A, Kumar M, Sharma S, Afzal K, Mehta A, Kalaivani M, Hari P, Bagga A (2015) Extending initial prednisolone treatment in a randomized control trial from 3 to 6 months did not significantly influence the course of illness in children with steroid-sensitive nephrotic syndrome. Kidney Int 87:217-224

8. Webb N, Trompeter R, Cummins C, Wheatley K, Frew E (2011) Long-term tapering versus standard prednisolone (steroid) therapy for the treatment of the initial episode of childhood nephrotic syndrome: national multicentre randomised double-blind trial. Available at: www.controlled-trials.com/ISRCTN16645249

9. Hahn D, Hodson EM, Willis NS, Craig JC (2015) Corticosteroid therapy for nephrotic syndrome in children. Cochrane Database Syst Rev 3:CD001533

10. Schulz KF, Chalmers I, Hayes RJ, Altman DG (1995) Empirical evidence of bias. Dimensions of methodological quality associated with estimates of treatment effects in controlled trials. JAMA 273: 408-412

11. Moher D, Pham B, Jones A, Cook DJ, Jadad AR, Moher M, Tugwell P, Klassen TP (1998) Does quality of reports of randomised trials affect estimates of intervention efficacy reported in meta-analyses? Lancet 352:609-613

12. Bagga A, Hari P, Srivastava RN (1999) Prolonged versus standard prednisolone therapy for initial episode of nephrotic syndrome. Pediatr Nephrol 13:824-827

13. Ehrich JH, Brodehl J (1993) Long versus standard prednisone therapy for initial treatment of idiopathic nephrotic syndrome in children. Arbeitsgemeinschaft fur Padiatrische Nephrologie. Eur J Pediatr 152:357-361

14. Hiraoka M, Tsukahara H, Matsubara K, Tsurusawa M, Takeda N, Haruki S, Hayashi S, Ohta K, Momoi T, Ohshima Y, Suganuma N, Mayumi M, West Japan Cooperative Study Group of Kidney Disease in C (2003) A randomized study of two long-course prednisolone regimens for nephrotic syndrome in children. Am J Kidney Dis 41:1155-1162

15. Lombel RM, Gipson DS, Hodson EM (2013) Treatment of steroidsensitive nephrotic syndrome: new guidelines from KDIGO. Pediatr Nephrol 28:415-426 